\title{
SIMULATION STUDY OF VARIABLE STRUCTURE CONTROL OF AN UNLOADED SYNCHRONOUS GENERATOR CONNECTED TO AN INFINITE BUS
}

\author{
E.H.T. EL SHIRBEENY*, N.S: AREF* AND \\ FATMA ABDEL AAL MOHAMED** \\ - National Water Research Centre, Cairo, Egypt. \\ - National Research Centie, Dokki, Cairo, Egypt
}

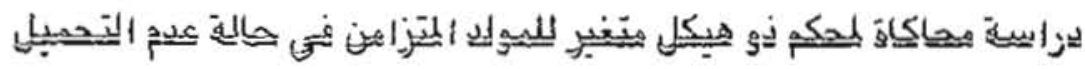

\begin{abstract}
ملفحسم

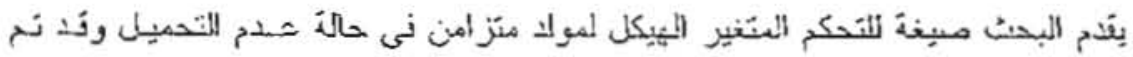

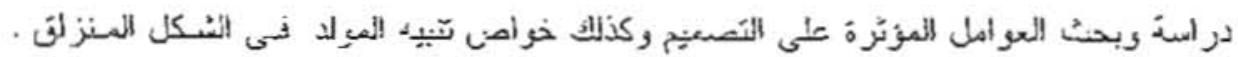

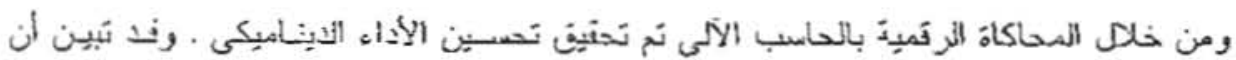

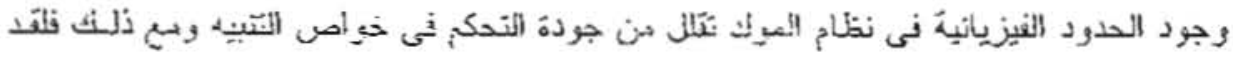

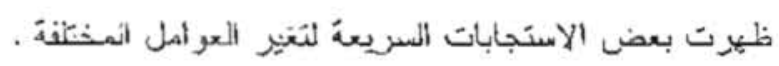

\section{ABSTRACT}

The formulation of a variable structure excitation control system is presented for a synchronous generator at no-load. Factors influencing the design are investigated and properties of the generator excitation in sliding mode are revealed. It has been verified through a digital computer simulation that an improved dynamic performance is obtained. The existence of physical limits in the generator system degrades the quality of variable structure excitation 
E.2 E.A.T. El-Shirbeeny, N.S. Sre? \& Fatma Abdel ha $\downarrow$ Mohaned

characteristics. However, other characteristics are maintained yielding quicker response and reduced sensitivity to parameter changes.

\section{INTRODUCTION}

In designing excitation control systems for synchronous generators, it is desirable to make the generator system insensitive to parameter variations and adjustable for improved dynamic performance [1]. Variable structure control techniques have been proposed [2,3] to achieve robust system performance. The variable structure excutation control differs from conventional control methods in that it changes the structure of the generator excitation systems. The sliding regime resolves the conflicting requirements in the desired generator performance demanding speed of response and high static regulation accuracy.

In this paper, the application of variable structure control theory is investigated using digital simulation for an unloaded synchronous generator connected to an infinite grid. The simplicity of the unloaded machine model enables a clear view in the inherent behavior of the variable structure excitation control. It has been a normal practice for installation engineers to consider the adjustment of excitation control parameters to optımise the generator performance during the initial testing stage, on-site [4]. The simulation study illustrates the main features of the variable excitation control indicating possible improvement in the dynamic system performance. The study includes the influence of control on speed of response, excitation effort, sensitivity characteristics and the role of excitation limits in relation with overall system performance. 


\section{SYSTEM MODEL}

Figure 1 shows a schematic representation of the syachronous generator system. The system incorporates an exciter and an electronic voltage regulator, AVR. The generator terminals are connected to an tafinite bus through a single tie-line. In this study two configurations are considered for the generator excitation control system [5]. The block diagram of this scheme is shown in Fig. 2 where she system model consists of the following elements:

I) Electronic amplifier

$$
G_{A}(S)=\frac{K_{A}}{1+S r_{A}}
$$

ii) Exciter

$$
G_{E}(S)=\frac{K_{e}}{1+S r_{\theta}}
$$

iii) Internal excitation stabilizer

$$
G_{p}(S)=\frac{K_{p}}{1+S T_{p}}
$$

iv) Synchronous generator at no-load

$$
G_{S}(S)=\frac{1}{1+S T_{d o}^{\prime}}
$$

The second configuration is in Fig. 3 where a variable structure excitation controlker is depicted. The controller-block consists of a logic element, switching elements, and a computation module. Only one feedback signal is required in this configuration. 
Taking the difference between in the generator output voltage signal and the desired voltage signal as e ( $t$ ), the state variables of the unloaded generator system can be defined as:

$$
\begin{aligned}
& X_{1}(t)=e(t) \\
& X_{2}(t)=X_{1}(t)
\end{aligned}
$$

The uncontrolled generator system equations are:

$$
\underline{X}(t)=\underline{A} \underline{X}(t)+\underline{B} u(t)
$$

where:

$$
\begin{aligned}
& \underline{A}=\left[\begin{array}{cc}
0 & 1 \\
-a_{1} & -a_{2}
\end{array}\right] \\
& \underline{B}^{T}=\left[\begin{array}{ll}
0 & -b_{1}
\end{array}\right] \\
& a_{1}=1 / T_{0} T_{d 0}^{\prime} \\
& a_{2}=a_{1}\left(T_{e}+T_{d 0}^{\prime}\right) \\
& b_{1}=K_{0} a_{1}
\end{aligned}
$$

Equation (7) represents a simple state-model of the syochronous machine with its excitation system and the generator is connected to an infinite busbar. The purpose of adopting such simple second order model is to demonstrate the influence of the variable structure control on the quality of the transient response of the generator excitation system, taking into account the excitation control effort and the sensitivity response 10 parameter variation. However, the system stability is not directly addressed but implicitly considered by judging the transient response of the system at no-load. Hence, a parallel correspondence has been created between the real 
commissioning situation for the adjustment of the generator excitation system and the simulation study. This is to obtain a useful judgment on the best machine performance following excitation parameter tuning.

The aim is to simplify the analysis, yielding practical results without consuming further computation efforts using bigher order models for the loaded machine.

\section{CONTROL IMPLEMENTATION}

The principle of variable structure control is based on designing a switching controller which changes from one structure to another following instructions received from a certain switching logic [6].

The logic operates according to the change of signs of the signal $R(\underline{X})$, where:

$$
\begin{aligned}
& X_{i}=X_{1} \\
& \delta(\underline{X})=\underline{C}^{\top} \underline{X} \\
& R(\underline{X})=X_{i} \delta(\underline{X})
\end{aligned}
$$

and $\mathrm{C}^{\mathrm{T}}$ is a switching vector which is given by:

$$
\begin{aligned}
& \underline{C}^{\top}=\left\{\begin{array}{ll}
C_{1} & 1
\end{array}\right] \\
& \underline{X}^{\top}=\left[\begin{array}{ll}
X_{1} & 1
\end{array}\right]
\end{aligned}
$$

Details on evaluating the switching vector $\underline{C}$ for higher order systems are given in Appendix I.

The choice of the switching vector $\underline{C}$ depends on the penalities imposed on the deviations of the controlled terminal voltage response. 
The switching hyberplane is defined by:

$$
\delta(\underline{X})=0
$$

The following equation gives the variable structure control law:

$u(t)=-\psi X_{1}(t)$

where:

$$
\Psi= \begin{cases}d & \text { if } R(\underline{X})>0 \\ f & \text { if } R(\underline{X})<0\end{cases}
$$

The values $d$ and $f$ represents positive and negative gains respectively. Their magnitudes are considered equal in this study.

The generator excitation control system operates in a sliding mode [7] if :

$$
\begin{aligned}
& \lim _{\delta \rightarrow+0} \frac{d \delta}{d t} \leq 0 \leq \lim _{\delta \rightarrow-0} \frac{d \delta}{d t} \\
& \text { or } \lim _{\delta \rightarrow 0} \delta \frac{d \delta}{d t} \leq 0
\end{aligned}
$$

provided that the following conditions are satisfied:

$$
\begin{aligned}
& C_{1}<\left[a_{2}+\left(a_{2}^{2}-4 a_{1}\right)^{1 / 2}\right] / 2 \\
& C_{1}>\left[a_{2}-\left(a_{2}^{2}-4 a_{1}\right)^{1 / 2}\right] / 2 \\
& d>\left[C_{1} a_{2}-a_{1}-C_{1}^{2}\right] / b \\
& f<\left[C_{1} a_{2}-a_{1}-C_{1}^{2}\right] / b
\end{aligned}
$$

Where: $a_{1}$ and $a_{2}$ are system design constants as defined above in the system model given by Eqn. (7) 
Figure 4 depicts a functional block diagram of the variable structure excitation controller. A feedback signal, $X_{i}(t)$, is derived from the generator terminal voltage variation. The signal $X_{1}(t)$ is required for computing logic and switching signals in the variable structure scheme. Although the switching vector, $C$, can be evaluated by the projector theory [8], it has been experimentally chosen to minimize the transient voltage-error signal and to decrease the transient sensitivity response of the generator system[9].

\section{SIMULATION ANALYSIS}

The simulation routine used for implementing the variable structure excitation control law is represented by the flowchart of Fig. 5. Initially, the control parameters, such as the coefficients of the switching vector, $C$, and the controller-gains, $d$ and $f$, are entered. Selection of "d- $f$ " parameters should be within the limits satisfying the conditions of sliding mode operation given by equations (20) and (21). Based on the polarity of the switching function, $R(\underline{X})$. decisions on changing the system structure are then taken.

Finally, the control signal, $u(t)$, is generated in an optimal sense. The control signal is then used to trigger the power circuit feeding the static excizer. The exciter output is the generator-field voltage. The overall digital simulation program is presented in Fig. (6). The simulation program accepts the system design and operating parameters and it computes the generator transient terminal response and the excitation control effort. A numerical integration routine, RKS, based on Runge-Kutta fourth order method with fixed step [10], is used to solve the system differential equations. 


\section{E. 8 E.H.T. El-Sh1rbeeny, N.S.Aref \& Facma Abdel Aal Mohamed}

Effectiveness of the variable structure excitation control strategy is tested by evaluating several performance indices at the end of every simulation run. An optimum dynamic system performance is judged by its to bring the generator terminal voltage variation close 10 zero, with minimum sensitivity to parameter performance, and without excessive expendiure of control effort [11]. The following perfornance indices are computed by the simulation programs:

i - Performance index to measure optimality of transient response characteristics

$$
J_{x}=\int_{0}^{c o} x_{1}^{2}(t) d t
$$

ii - Performance index to measure the quality of control effort:

$$
J_{\mathrm{u}}=\int_{0}^{\infty} U(t) d t
$$

iii-Performance index to measure system response sensitivity to changes in the design parameter, (P);

$$
J_{S}=\int_{0}^{\infty} S_{p}(t) d t
$$

Table (l) gives the nominal values of the design parameters of the staric exciter and the synchronous generasor used in the simulation program.

Table 1: System design parameters

\begin{tabular}{|l|l|}
\hline Exciter & Generator \\
\hline $\mathrm{K}_{\mathrm{e}}=40$ & $\mathrm{~T}^{\prime} \mathrm{do}_{\mathrm{o}}=3.46 \mathrm{sec}$. \\
$\mathrm{T} e=0.05 \mathrm{sec}$. & \\
\hline
\end{tabular}

BU日FATMA-0) 


\section{SIMULATION RESULTS}

\subsection{Transient response}

Several parameters have been tried for the conventional and variable structure excitation control schemes. The purpose is to obtain optimum control parameter settings for both control methods so that a reasonable reference base can be considered for comparison, Table 2 gives set-values of the excitation control parameters.

Table 2: Parameter settings for two excitation control methods

\begin{tabular}{|l|c|}
\hline Conventional & Variable structure \\
\hline$K_{P}=0.03$ & $\mathrm{~d}=5$ \\
$\mathrm{~T}_{\mathrm{P}}=1.00 \mathrm{sec}$. & $\mathrm{f}=-5$ \\
$\mathrm{~K}_{\mathrm{A}}=10$ & $\mathrm{C}_{\mathrm{i}}=15$ \\
$\mathrm{~T}=0.02 \mathrm{sec}$. & \\
\hline
\end{tabular}

Figure 7 shows the computed dynamic error responses of the generator excitation control systems for a step change in the reference voltage signal. The transient response of the excitation control signal is shown Fig. 8. A detailed comparison of the responses for the conventional and variable structure control methods are given in Table 3, based on the computer simulation results, several observations are in order:

a) On comparing the transient excitation error responses, it can be seen that a great improvement in the dynamic performance of the synchronous generator system has been obtained in the case of variable structure control. The variable structure excitation system is faster as judged by its settling time of 0.41 second when

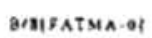


E.10 E.H.T. פl-Shirbeeny, N.S.Arsf \& Fatma Abdel Aal Mohamed compared with that of conveational excitation control having a settling time of 2.8 seconds. No overshoot is observed with variable structure control. Moreover, the conventional excitation control suffers from an osciilatory dynamic response. The quality of variable structure response is measured by a performance index, $\mathrm{J}$, of 0.230 ? which is lower than that computed for conventional excitation control having a value of 0.5756 .

b) Examining the transient excitation control signal curves of Fig. 7, it is seen that the energy required to generate the excitation control effort is very much reduced using variable structure control strategy, The computed control effort, J, for variable structure control is 605.26 which is three times lower than that for the conventional excitation system having an index of 1888.62 .

Table 3: Comparison of dynamic performance characteristics

\begin{tabular}{|l|c|c|}
\hline \multicolumn{1}{|c|}{ Computed Attribute } & Conventional & $\begin{array}{c}\text { Variable } \\
\text { structure }\end{array}$ \\
\hline 1. Settling Times, s & 2.8 & 0.41 \\
2. Maximum overshoot, \% & 20 & 0 \\
3. Voltage response index, $\mathrm{J}_{\mathrm{X}}$ & 0.5754 & 0.2301 \\
4. Control effort index $\mathrm{J}_{\mathrm{U}}$ & 1888.62 & 605.26 \\
\hline
\end{tabular}

\subsection{Switching Characteristics}

The operation of variable excitation control system in sliding mode is the main reason of obtaining a fast system response witbout oversboot. The larges the values of " $\mathrm{f}$ " and " $\mathrm{d}$ " gains the faster the representing point will reach the switching line and the smaller 
the steady state error will be. Once the representing point reaches the switching line, the excitarion system equation of motion becomes:

$C_{1} X_{1}(t)+X_{2}(t)=0$

Equation (2S) is a first order differential equation describing the generator dynamics without overshoot. To demonstrate the effect of $C_{1}$ on the speed of system response, three representative values were chosen. Increasing $C_{1}$ from 5 to 15 decreased the settling-time of the transient response from 1.25 seconds to 0.44 second. The simulation results shown in Fig. 9 demonstrate the influence of switching parameter $C_{1}$.

\subsection{System Sersitivity}

To test the robustness of the synchronous generator excitation system, the dynamic sensitivity functions of the system voltage to changes in the system design parameters are computed [12]. Severai sequential variations have been introduced in the dominant system design paramesers at no-load. The computed dynamic sensitivity responses are shown in Fig. 10. When comparing the sensitivity of variable structure excitation with that of conventional excitation, it is observed that variable structured control casuses a drastic reduction of terminal voltage sensitivity to variation in generator open circuit time constantas shown in Fig. 10.a. The computed sensitivity performance index, $J_{5}$, in case of variable structure control is 0.175 which is very much lower than of the conventional voltage regulator system having a corresponding senstivity index of 4.901 . Fig. 10.6 depicts the sensitivity functions of the generator terminal voltage with respect to the exciter design parameter $\mathrm{K}_{\mathrm{e}}$. 
The variable structure excitation control still exhibits a lower sensitivity which is weighted by an index of 0.38 The corresponding sensitivity index for the conventional excitation control is 3.835. The sensitivity transient response of generator voltage with respect to changes in the exciter time constant, $T_{c}$, is shown in Fig. 10.C Comparing the sensitivity indices in this case it is found that it is 0.47 for variable structure control and 1.58 for conventional excitation control. The above simulation results have shown that the variable structure excitation control is not sensitive to changes in system parameters. This demonstrates a salient feature of operating the excitation system in a sliding mode.

\subsection{Excitation Limits}

Physical limits exist within different parts of synchronous generator excitation system. The limits include hard an soft saturation characteristics of electronic amplifiers and magnetic circuits inside the machine. The nonlinear nature exerted by these timits is usually reflected on the quality of generator dynamic performance. To study the influence of excitation limits, hard limits have been simulated as iroposed on the controller out-put. The variable structure control parameters chosen in this part of the simulation study are:

$$
\begin{aligned}
& C_{1}=15 \\
& \mathrm{f}=-5 \\
& \mathrm{~d}=+5
\end{aligned}
$$

Three levels of hard limits are tried in the simulation runs. They range from +1.5 to +3.75 p.u. The control effort performance index, $J_{Q}$, has been computed for every limit and the results are given in Table 4. It is seen that the control increases as limits are decreased. The variable structure control pushes the excitation control signat in a direction to compensate for the limited bounds imposed on the signal variations. The B/S(FATMA.0) 
action is necessary for the excitation system to reach the sliding mode. However, the presence of limits on the control signal, slows down the overail system response, as can be observed from the error transient curves in Fig. 11. Increased setting timc in this case is caused by the delay of switching operation inside the controller.

Table 4: Influence of excitation limits

\begin{tabular}{|c|c|}
\hline P.U. limits & Control effort index \\
\hline+1.5 & 1.025 \\
+2.5 & 0.985 \\
+3.75 & 0.860 \\
no limits & 0.610 \\
\hline
\end{tabular}

\section{CONCLUSION}

The paper presented a study of variable structure excitation control of an unloaded synchronous generator which is connected to an infinite bus by a tie-line. A digital simulation study has been conducted to investigate various aspects of system's performance. Operational characteristics of the synchronous generator with excitation in sliding mode are strongly improved.

The performance of the synchronous generator at no-load has been compared with that obtained using conventional excitation controllers. Simulation results bave shown that variable structure control reduces the system sensitivity 10 variations in its design parameters. A proper choice switching parameters and controller's gain will yield a better dynaraic performance than the conventional excitation controller, in terms of quicker response and smaller control effort. The influence of system nonlinearities represented by limits on the control signal has been aiso investigated. Although control limits degenerate 
the improved dynamic system performance, the variablc structure excitation control is still better than conventional control methods.

\section{LIST OF SYMBOLS}

\begin{tabular}{|c|c|c|c|}
\hline & $=$ switching vector & s & = laplace operator. \\
\hline f & $\begin{aligned}= & \text { variable structure control- } \\
& \text { ler's gains. }\end{aligned}$ & $S_{p}(t)$ & $\begin{aligned}= & \text { transient sensitivity } \\
& \text { function with respect }\end{aligned}$ \\
\hline$(\mathrm{t})$ & $\begin{aligned}= & \text { transient excitation error } \\
& \text { signal. }\end{aligned}$ & & 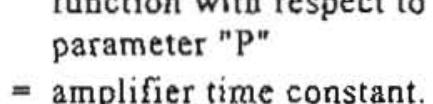 \\
\hline $\mathrm{G}(\mathrm{s})$ & $=$ transfer function & $T^{\prime}$ do & $=$ dire \\
\hline$J_{\mathrm{x}}$ & $\begin{aligned}= & \text { transient response } \\
& \text { performance index. }\end{aligned}$ & & \\
\hline$J_{1}$ & $\begin{array}{l}=\text { sensitivity perfürmance } \\
\text { index. }\end{array}$ & $\begin{array}{l}\mathrm{Te} \\
\mathrm{U}(\mathrm{t})\end{array}$ & $\begin{array}{l}\text { constant. } \\
\text { ntrol signal. }\end{array}$ \\
\hline $\mathrm{Ju}_{u}$ & $\begin{aligned}= & \text { control effort } \\
& \text { Performance index. }\end{aligned}$ & $\begin{array}{l}V(t) \\
V f(t)\end{array}$ & $\begin{array}{l}=\text { terminal voltage. } \\
=\text { generator fieid voltage. }\end{array}$ \\
\hline CA & $=$ amplifier gain. & VR & $=$ reference input signal. \\
\hline & $=\mathrm{ex}$ & V & \\
\hline & $=$ stabilizer gain. & $\underline{x}$ & $=$ state-vector \\
\hline
\end{tabular}




\section{REFERENCES}

[1] Kabriel, B.J., "Simple formulas for voltage regulator gains for best alternator stability". Proc. IEE, Vol. 116, No. I1, pp Nov. 1969, 1907-1914.

[2] Utkin, V.l. "Variable structure systems with sliding modes" “IEEE Trans., AC-22, pp. 212-222 1977.

[3] Rahim, A., and Nassimi, S., "Synchronous generator damping enhancement through coordinated Control of exciter and SVC". IEE Proc. Generation, Transmission and Distribution, Vol. 143, No. 2, pp 211-218, 1996.

[4] Winning, D.J.; El-Shirbeeny, E.H.M; Tompson, E.C.M and Murray-smith, D.J.,: "Sensitivity Method for online optimisation of a synchronous-Generator excitation controller", Proc. IEE, V.124, No. 7, PP. $631-638$ July i 977.

[5] Mielczarski, W., and Zajaczkowski, A., "Nonlinear field voltage control of asynchronous generator using feedback linearization, Automatica, 30. PP 1625-1630 Oct. 1994.

[6] Itkis, U., "Control systems of variable structure", Book, John Wiley \& Sons, N. Y., 1976.

[7] N.S. Aref., "Variable structure control of synchronous machines", M.Sc. Thesis, University of Technology, Baghdad, 1983.

[8] El-Ghezawi, O.M.; Zinober, A.S. and Billings, S.A. "Analysıs and design of variable strucrure systems using geometric Approach", Int., 3. Control, 38, pp. 657, 1983.

[9] Utkin, V, "Sliding modes and their application in variable structure systems, MIR publishers, Moscous, 1978.

[10] Coughanowr. D., "Process systems analysis and control". MicGraw-Hill Co., N.Y., 1991.

[11] Lahdhiri, T. and Alouani, A. "Nonlinear excitation control of a synchronous generator with implicit terminal voltage regulation", Electric Power Systems Research, V.36, No. 2, 1996, pp 101-112.

[12] Tomovic, R., "Sensitivity analysis of dynamic systems "Book, McGraw-Hill Co., NY., 1963. 


\section{APPENDIX I}

\section{Evatuation of Switching Vector for Higher Order Systems}

For a system of an order $n$, it can be represented by the following state-model:

$d X_{i} / d t=X_{i+1}$

$$
i=1,2, \ldots, n-1
$$

$d X_{b} / d t=-\sum_{i=1}^{n} a_{i} X_{i}-b u$

where: $a_{i}$ is system design constant. To implement variable structure control strategy, the control law will be given by:

$u=\psi_{1} X_{1}$

$\psi_{1}=\left[_{f}^{d}\right.$

if $\delta \cdot X_{1}>0$

if $\delta \cdot X_{1}<0$

where:

$$
\begin{aligned}
& d=\text { positive gain } \\
& f=\text { negative gain } \\
& \delta=\sum_{i=1}^{n} C_{i} X_{i}
\end{aligned}
$$

and

$$
C_{1}=\text { positive constant } \text {. }
$$

The model of the variable structure controlled system becomes: 


$$
\begin{aligned}
& d X_{i} / d t=X_{i}+1 \quad i=1,2, \ldots, n-1 \\
& d X_{a} / d t=-\sum_{i=1}^{n} a_{i} X_{i}-b w_{2} X_{1}
\end{aligned}
$$

For the system to reach the sliding mode, the following condition should be satisfied:

$$
\operatorname{Lim}_{\delta \rightarrow 0} \delta d \delta / d t \leq 0
$$

Applying the condition of Eq. (A-5) on the system described by Eqn. (A-4), we get:

$$
\begin{aligned}
& d \delta / d t=d X_{n} / d t+\sum_{i=1}^{n-1} C_{i} d X_{i} / d t . \\
& =-\sum_{i=1}^{n} a_{i} X_{i}-b \Psi_{1} X_{1}+\sum_{i=1}^{a-1} C_{i} X_{i+1}
\end{aligned}
$$

\section{When:}

$$
\begin{aligned}
& \delta=0 \text { Equation }(A-3) \text { becomes: } \\
& X_{n}=-\sum_{i=1}^{n-1} C_{i} X_{i}
\end{aligned}
$$

Substisuting for $\mathrm{Xn}$ from $\mathrm{Eq}$. (A-7) into Eq. (A-6), we get

$$
\begin{aligned}
d \delta / d t=\sum_{\delta=0}^{n-1}\left(C_{1-1}-a_{i}\right. & \left.+C_{1} a_{n}-C_{i} C_{n-1}\right) X_{i}+\left(C_{1} a_{n}-a_{1}\right. \\
& \left.-C_{1} C_{n-1}-b \psi_{1}\right) X_{1}
\end{aligned}
$$


E.18 E.H.T. El-Shırbeeny, M.S.A rei \& Fatma Hodel Aal Mohaned

The constants of the switching vector $\underline{C}$ can be obtained from the following relations satisfying Equations (A-8) and (A-4):

$$
\begin{aligned}
& C_{i-1}-a_{n}=\left(C_{n-1}-a_{n}\right) C_{1} \quad i=2,3, \ldots, n \\
& f \geq\left(-a_{1}+C_{1} a_{n}-C_{1} C_{n-1}\right) / b \\
& d \leq\left(-a_{1}+C_{1} a_{n}-C_{1} C_{n-1}\right) / b
\end{aligned}
$$




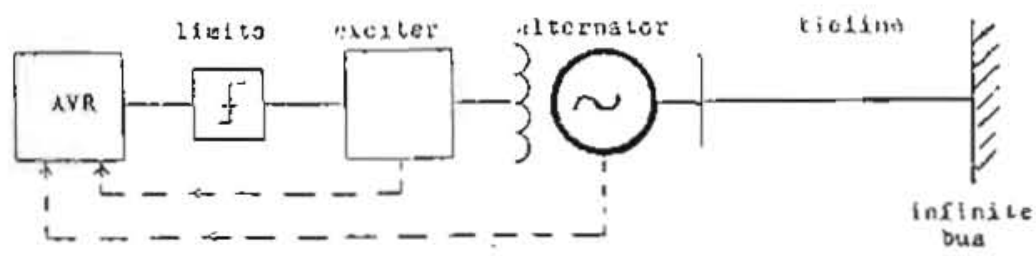

Fi5.t Schematic disgran of cenerdtor system.

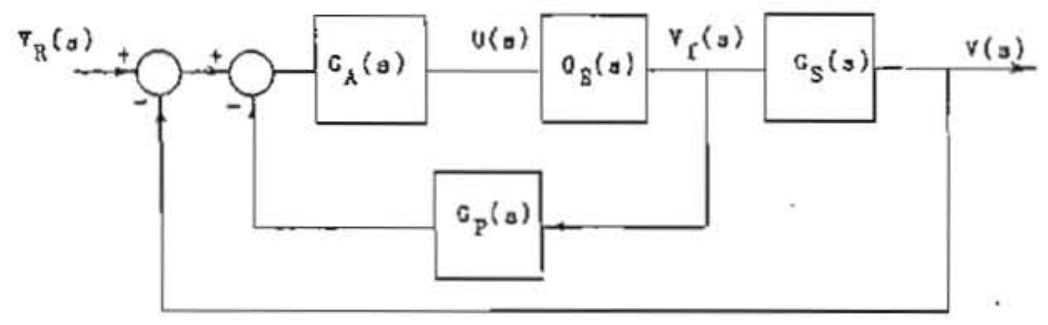

Pig. 2 Conrentional excitation.

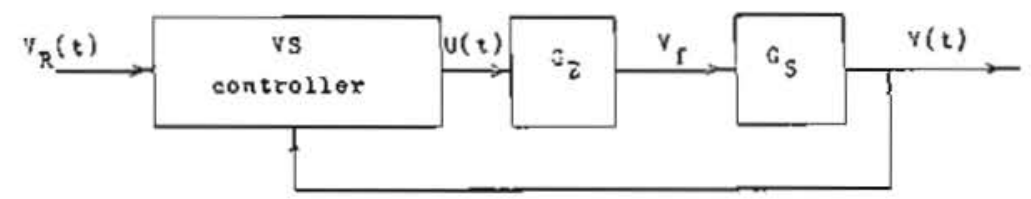

Flg.3 Variabis etructuro excitation systed. 


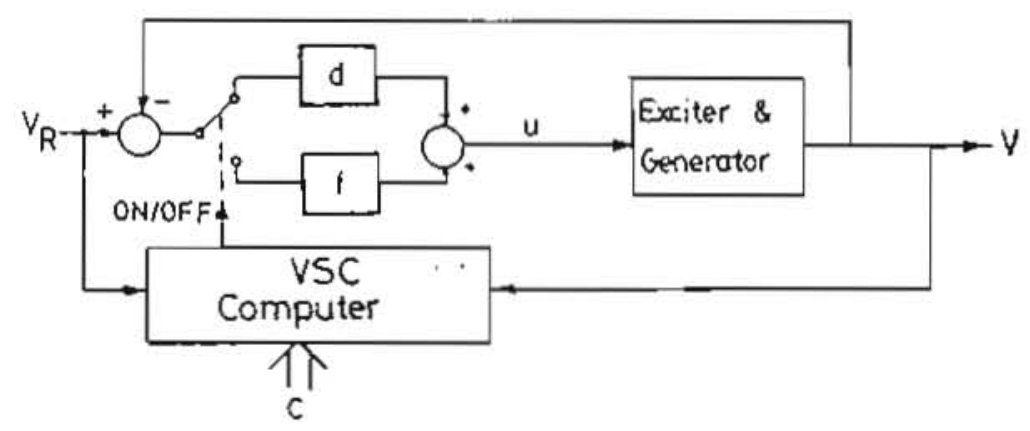

Fig. 4. Implementation of variable structure excitation.

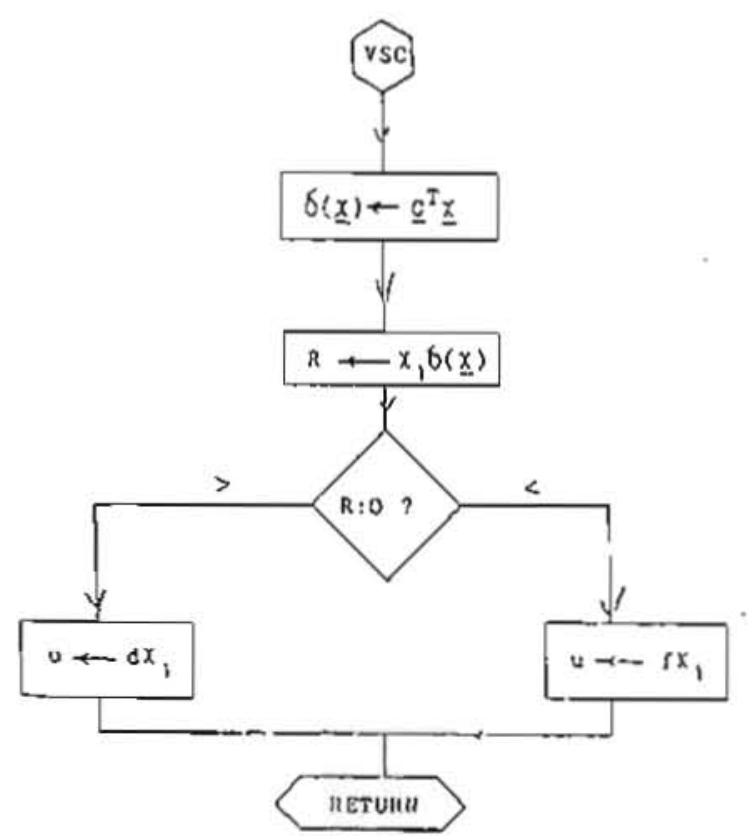

Fic.5 Valsable viructure control reusino. 


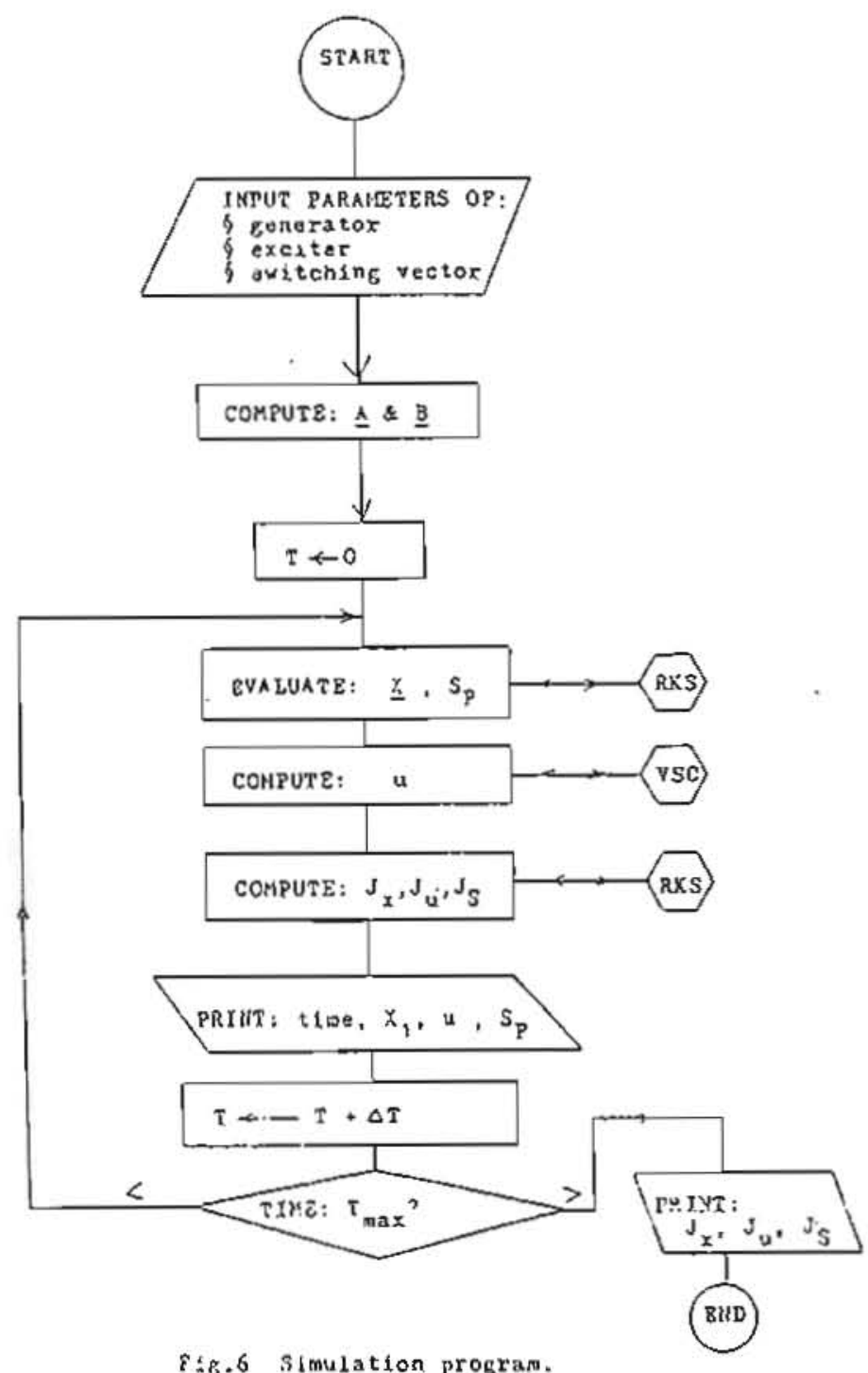




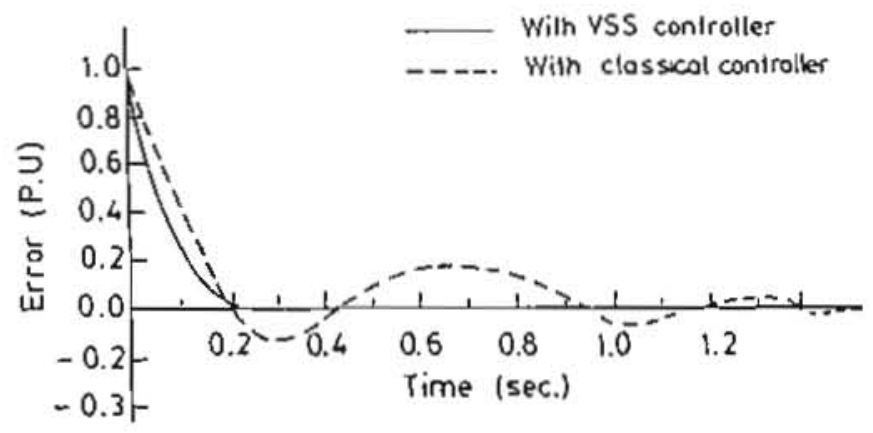

Fig. 7 . Excitation error transient response curves.

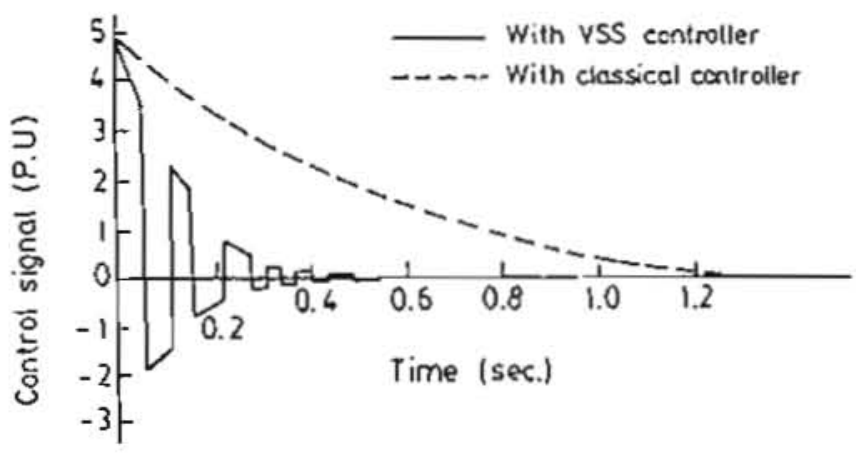

Fig. 8. Control signal transient sesponse curves. 


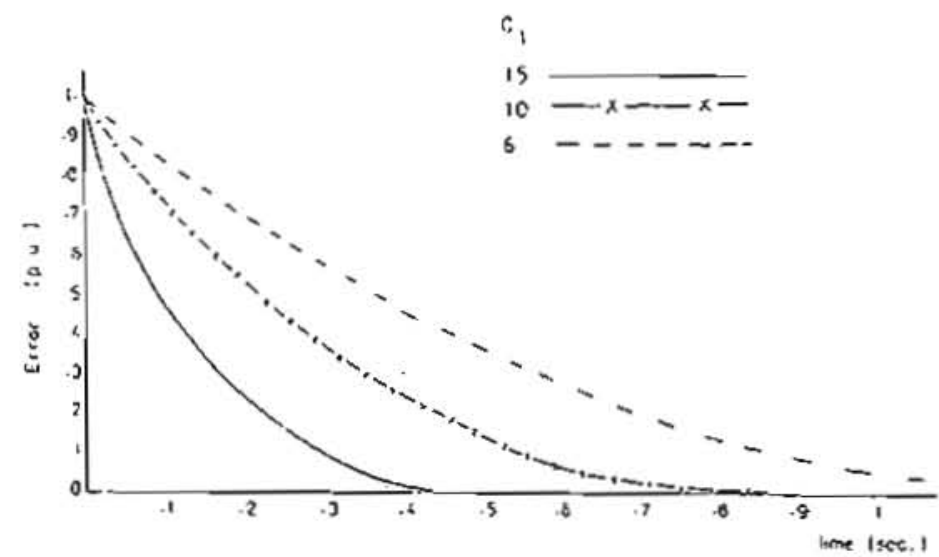

Ple.s Influence of sxitching rector on speed of reapanse.

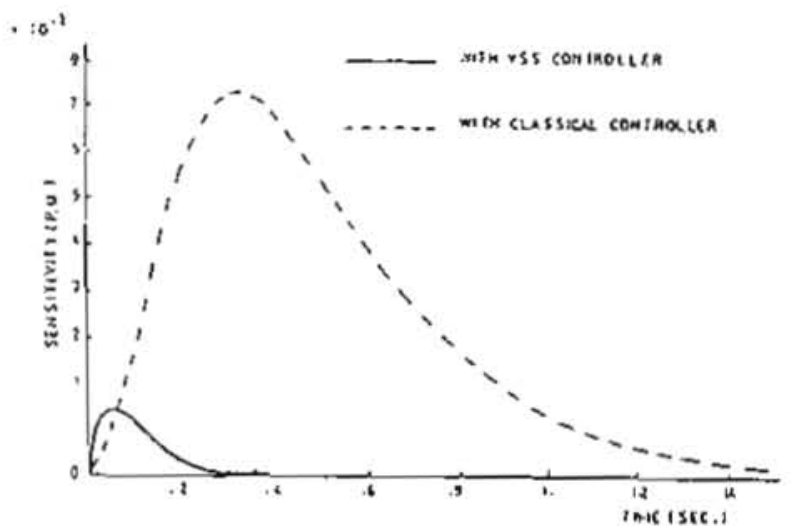

Fig.10a Seastivity comparizon with caspeet to Ido. 
E.24 E.S.T. El-Shirbeeny, N.S.Aret \& Fatma Abdel Âl Mohamed

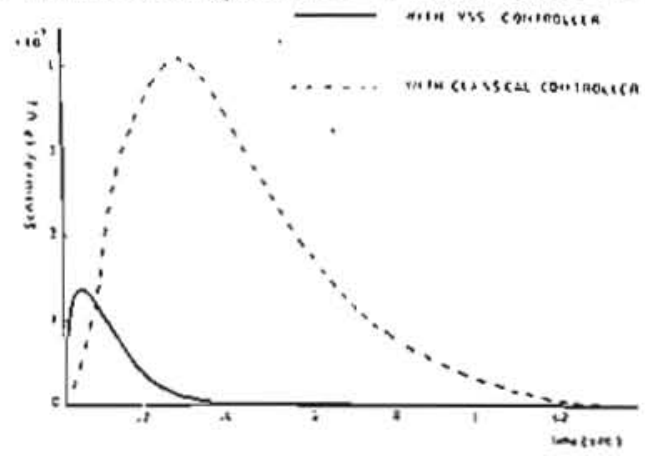

Piz. $10 b$ Senafterity cooparioon with rageet to Ke.

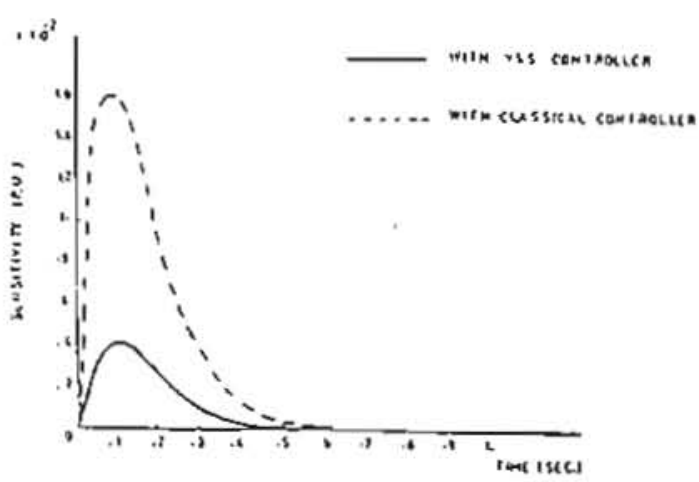

Fic. Inc Senstitivity comparison vill, respect to Te

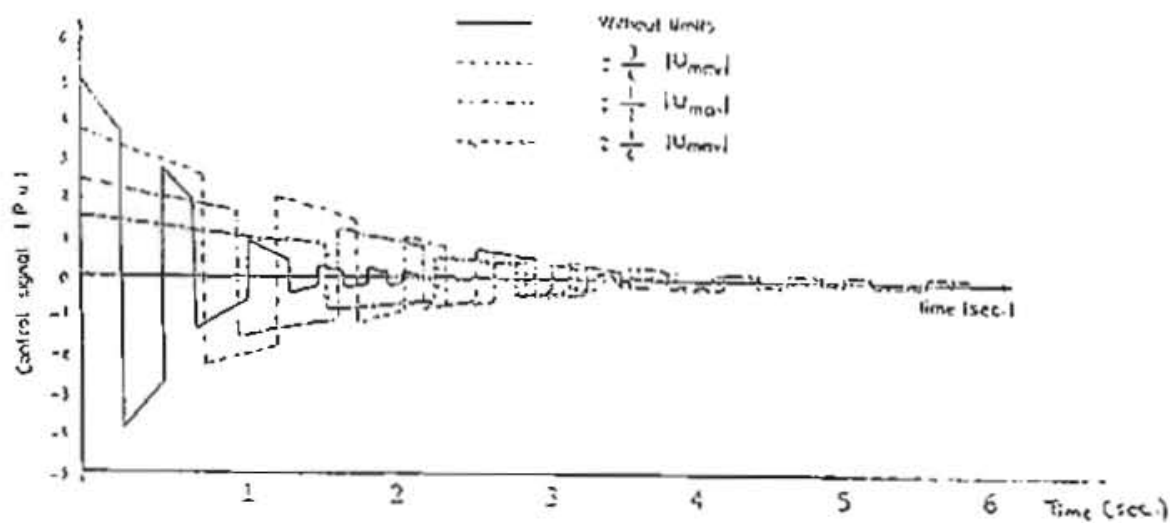

Fic. In Influence of excltation liofta on concrol cienal translent conponae. 